\title{
When Economics meets Ethics : the Governance of Economic Activities in the Information Society
}

\author{
Eric Brousseau \\ University of Paris X \\ Institut Universitaire de France \\ EconomiX \\ eric@brousseau.info
}

\begin{abstract}
Can economics be of any use to design - or at least to think institutional frameworks that would meet the necessary ethical requirements to govern the information society? By relying on a survey of the economics of institutional design in which two types of tradeoff -centralization vs. decentralization and public vs. private provision of orders - are highlighted, the paper points out that the current global context is specific as compared to national ones, especially because there is no powerful central authority able to act as a last resort regulator and promotor of the "collective" interest. This is a challenge in the digital world due to the specificities of the information based and digital technologies based activities in which excessive monopoly capture by groups of interest could occur. These call for the emergence of authorities able to centrally provide order in last resort. This does not mean that self and local governance are not needed. The paper simply claims that they should be complemented by a global provision of public order. Various paths of emergence of such central provision are described and briefly discussed.
\end{abstract}

Keywords: Multilevel Governance, Public vs. Private Institutions, Network Effects, Institutional Framework, Internet Governance

Can economics be of any use to design - or at least to think - institutional frameworks that would meet the necessary ethical requirements to govern the information society? The author of these lines is quite unable to reply to this question. He can however provide the reader with recent advances in the economics 
of institutional frameworks that could be considered of some use to think, if not optimal, at least better frameworks to govern the information society.

Before doing so, some linguistic/conceptual precisions are needed. In what follows we use the very broad notion of governance to describe the activities needed to produce an order allowing the considered elementary units forming the society to coordinate. Governance results from the combination of two activities: designing rules and ensuring their compliance. The considered rules are those that delineate and allocate rights of access and rights to use resources to agents interacting in a common (economic) space. In concrete terms, these rules correspond to the property rights system (that delimit and allocate basic rights of access and use), the contract law (which establishes how these rights can be split and transferred among agents), the various regulations (which impose constraints to agents on how they shall use resources to manage various collective issues; in particular in case of interdependencies among their actions, in case of common ownership, and when there are risks of abuse of dominant positions).

Economics considers the advantages of alternative ways of establishing and enforcing orders in a given society. In particular it insists on two trade-offs. The first one is a centralization/decentralization one. Indeed, a uniform order can be centrally provided to the whole society, meaning that all the agents comply with a common set of rules implemented by a mechanism that overhang the whole society. Alternatively the collective order can result from bilateral (contractual) arrangements; resulting in a collection of heterogeneous and local orders issued by the "basis". Economics recently developed a cost/benefit analysis of the provision of an order at different degrees of centralization. The analysis points out in particular that neither pure centralization nor pure decentralization are efficient, and that efficiency results from the multilevel provision of an order.

The second tradeoff is between the provision on an order by a public or by a private entity. Indeed any collective order results from a delegation established between the individuals who will comply with the order and an entity responsible for establishing it. This entity can be of different type. It can be an individual or an informal group. It can also be, and often is, an organization. A contrast can be established between two types of delegation. A "strong" delegation - which is at the root of a public order - means that individuals recognize a wide area of authority to the "entity", because they ask this entity to establish and defend their fundamental individual rights (whatever they are). To the opposite a "weak" delegation — at the source of a private order - provides a limited authority to establish and enforce rules in a bounded set of domain of actions. In both cases, individual recognize that the production of individual rights - opposable to third parts - is partly a problem of collective action because these rights have to be mutually recognized and because they have to be established against others (which makes it worth to benefit from economies of scale). Recognizing rights to command - which is authority - to an entity which will benefit the same recognition by other individuals, will allow this entity to become a mutual guarantor among those who accept to subordinate to it as well as an aggregator of individual coercion means to constrain those who do not delegate any task to this entity to recognize the rights of those who delegate the duty to actually establish their individual rights. Since we assume that individuals are able to rank the types of rights they are delegating from more to less fundamental, one 
assumes that they are ready to pay a higher price - to accept a wider renunciation of individual sovereignty - to guarantee their essential rights. This leads to contrasted types of delegations resulting in contrasted ability and "legitimacy" of various types of authorities in establishing a collective order. From the point of view of individuals, it results in a tradeoff between costs (in terms of sovereignty) and benefits (in terms of strength of rights).

To a large extent, the centralization vs. decentralization tradeoff is parallel to the public vs. private trade-off when one considers the provision of an order at the national level. Indeed in that case, the most-central/highest-level of governance is the State, while many of the entities that decentrally organize regulations for sub-sets of the nation are either totally private (as in the case of self-regulations provided by professions), or are weak public entities in the sense that in a Nation-State the strongest "public" delegation is to the national government, not to the local ones. The later are generally only responsible for providing order and services aimed at dealing with the citizens' day-to-day life, while the central government is responsible for guaranteeing their fundamental rights. This parallel no longer holds when one considers the global context.

The aim of this paper is to provide lenses to better understand the stakes and the trade-off behind institutional choices in matter of governance frameworks for the information society. It is clear however that there is no single theory to provide an optimal institutional design, nor recipes to reach it. Our goal is simply to provide the reader with an analytical framework that could be useful when considering the issues of the governance of the Internet and of the information society (which are in this paper considered as closely linked issues since the technical management of the infrastructure and its contents influences directly the rights of uses and rights of access over information and digital devices, and as a consequence the governance of activities performed on-line or thanks to digital technologies). However, one must point out that the proposed framework is not at all specific to the analysis of the Internet. The regulation of the Internet, and more generally of the information society, is simply another domain of global governance that raises the issue of central government's scattered authority, upwards to supranational entities, downwards to sub national jurisdictions, and sideways to public/private networks ${ }^{1}$.

The paper is organized as follows. It starts with a presentation of the economics of institutional design in which the two types of tradeoff highlighted above are presented (section 1). It then explains why the current global context is specific as compared to national ones, especially because there is no powerful and central authority able to act as a last resort regulator (section 2 ). This is a challenge in the digital world due to the specificities of the information based and digital technologies based activities (section 3 ). Thus, both the general theory and the

1 Two bodies of economics literature have investigated these notions in particular. Neoclassical political economists and public choice theorists (e.g. Elinor Ostrom and James Walker, 1997; James Rosenau, 2001) insist on the idea that governance results from the setting of dispersed self-rule on the part of diverse voluntary groups that overlap and interact in a complex way among each other and with imperfect markets and imperfect public-interest seeking institutions. Theorists of (fiscal) federalism have gone from studies focused primarily on formal constitutional federations to a costs/benefits analysis of centralization vs. decentralization of authority (e.g. Wallace Oates, 1972, 1999). 
specificities of the Internet based information society call for the emergence of instances able to centrally provide order in last resort. This does not mean that self and local governance are not needed. The paper simply claims that they should be complemented by some public and global provision of order. Various paths of emergence of such a central provision are described and briefly discussed (section 4).

\section{The Economics of Institutional Design}

\subsection{The centralization vs. decentralization tradeoff}

Behind the economics of institutional design lies the idea that an institutional system results from a human activity consisting in building coordination means allowing agents to coordinate in using the resources available in a given economic space. Alternative institutional frameworks grant agents with different (individual and collective) capabilities for using resources, producing new ones, and accumulating, in particular because they impact on individual incentives and freedom to use and transfer resources and on collective capabilities to share risk and mutualize resources, which overall result in contrasted capabilities to allocate resources to their most efficient use, and in diverse dynamics of accumulation and innovation. Also, alternative institutional frameworks correspond to different quantities of resources spent to establish an order since means and efforts have to be dedicated to the design of rules and to guarantee their enforcement. A given organization of an institutional framework therefore results in an economic outcome - that can be summed up in terms of wealth or growth - and in costs. The "production" of an institutional framework can thus be analyzed as an economic activity, of which benefits/costs performance is dependant upon the degree to which it is centrally (or decentrally) provided.

Following the seminal contributions by Oates (1972, 1999), Barzel (1989) and North (1990), and more recently by Greif (2006), economists have been dedicating several applied and theoretical analysis of the economics of centralization vs. decentralization of the provision of an order. Part of this literature has recently been tentatively synthesized by Brousseau \& Raynaud (2006, 2007). The analysis is summed-up below.

It is important to point out two essential assumptions behind the analysis. First, agents are supposed to be heterogeneous meaning that they have different endowment, and different preferences, and different localization in the networks structuring a society. Therefore, they have contrasted coordination needs and specific preferences on the matter when considering each of their potential counterparts in possible interactions (because of both parts' characteristics and because of the purpose of their transactions). Thus, they have an intrinsic preference for diversity and even customization of their relationships' governance (which translates into a strong willingness to sign bilateral contracts to govern them). Second, agents care about the (transaction) costs they individually bear, not about the transaction costs born by the society in general. Since they are in asymmetric situation - which relates to the hypothesis according to which they have different endowment and different localization in relational networks - some individuals have the ability to impose to others rules that fit better to the preferences of the former than to those of 
the later (see Brousseau and Raynaud (2006) for details). Orders are built around kernels of agents sharing close preferences in matter of coordination, meaning that they can agree on a set of rules reducing transaction costs among them. Other agents that may have different preferences can have interest to adopt the same rules, because they reduce their coordination costs as compared to non-adhesion, if alternative collective coordination solutions are not available. However, alternative set of rules if they exist, would better meet their needs. Thus, individuals could well adopt rules designed by the members of the kernel even though they are not their first choice solutions. This results into the idea that a given order, whether it applies to a pair of agents, to a community or to the whole society, is designed to minimize the costs (and maximize the benefits) of some core members, while it does not fit perfectly with the preferences of marginal members (which therefore benefit of a lower benefits/costs ratio than core members). Collective orders are therefore made of various "circles" of individuals adopting rules designed to meet, above all, the coordination needs of a kernel. Those who are in circles far from the kernel have to incur higher costs of coordination than they would, in an ideal world, in which they would coordinate according to their preferences. They incur maladaptation costs defined as the difference between their first best solution and the cost of the available solution. Orders are therefore "centered" and "sponsored"; some individuals had in the past interest in promoting the use of their preferred rule by others, and were successful in inciting them to adopt $\mathrm{it}^{2}$.

Following this "vision", one can pinpoint a reduced number of factors influencing the benefit/cost ratio of settling rules and organizing enforcement centrally or decentrally in a given society. Centrally means that a common order applies to the whole society. Decentrally means that different orders co-exist. Full decentralization means that only bilateral orders are established by contracts among the members of the society. Intermediate decentralization, means that self-regulated communities co-exist (and overlap). One important consequence is that the more centrally provided an order, the more mandatory the order for the individuals as they have fewer alternative (exit) options. In case of full centralization individuals do not have any possibility to adhere to an alternative collective order, while with an increasing degree of decentralization in the provision of order(s), individuals tend to have wider choice in matter of alternative orders to adhere to.

In a first analytical step, the costs and the benefit of settling an order on a more centralized basis (which can be read as the benefits and the costs of settling a social order on an increasingly decentralized basis) are highlighted. The "centralization vs. decentralization" trade-off is explored. In a second step, the way a social order may result from the establishment of partial orders at different levels of centralization/decentralization, allows to explore the economics of multilevel governance.

2 Here our analysis fits with the economics of social networks applied to "star networks", i.e. networks centered on a pivotal agent linking all the other members of the network (see Hanneman and Riddle, 2005, for an overview of this literature). In these networks, "closeness" (Bonacich, 1987) - i.e. the number of links between individuals - of an individual to the center refers directly to the degree of convergence of individual preferences in matter of coordination (i.e. agents in the kernel share closer coordination needs than those distant from it). 
The benefits of centralization (which are therefore also the cost of decentralization) are due to the combination of three effects

- scale and scope effects: the wider the community to which a common system of rules applies and is made enforceable by common means, the more the fixed cost of designing rules and establishing means of supervision/constraints can be shared among the members;

- learning and specialization benefits: the wider the community to which an order applies, the easier it is to dedicate specific means and to specialize them in designing efficient principles of coordination, in supervising agents, in developing means to constrain them.

- reduction of collective welfare losses: when an order is designed/enforced at a collective level, interdependencies among individuals are taken care of (are internalized), whereas several orders co-exist they can be partly incompatible, resulting in higher costs of coordination among individuals complying with heterogeneous orders and in externalities among communities ${ }^{3}$.

Thus the more unique the order applying to a society, the less inconsistencies among local arrangements, and the wider internalization of externalities, and the higher is the creation of positive network effects ${ }^{4}$ due to the use of common rules.

On the other hand, centralization generates inefficiencies due to

- (static) maladaptation: the more central is the provision of an order in a given society, the increasing heterogeneity of individual preferences and coordination needs, to which common solutions are applied. Thus, the increasing share of individuals who have to comply to coordination principles that are not their first best; and the wider the gap between the preferences of the members of the kernel and the members of the marginal circles of the community. The more centrally provided the order, the higher maladaptation costs in the society.

- (dynamic) maladaptation: the larger the community to which a common order applies, the more difficult it is to manage adaptations to evolving coordination requirements. Indeed renegotiations of the rules are more difficult to organize due to the wider heterogeneity of preferences. In addition, since core members being able to externalize costs on the other members of the community (who have less exit options when the order is more centrally provided), they have fewer incentives to adapt to new requirements. The more centrally provided an order, the less likely it is to adapt to needed changes, resulting in higher maladaptation costs.

\footnotetext{
3 An externality is an interdependence among economic agents that is not taken into account by the economics system - by the price system - and generates therefore biased decisions (about the use of resources), because those who make decisions do not incur the actual cost of using resources.

4 A network effect is a specific type or externality due to networking among individuals. The higher the number of user of a network (whether it is a physical resource, as a telecommunication network, or an intangible resource, like a technical standard - which is a rule -, the wider benefit each individual user gets from the network. Positive networks externalities can however be inhibited by congestion effects (that applies especially for physical resources).
} 
- Higher information asymmetries: the larger the community, the more difficult it is to supervise members of the community because information asymmetries cumulate. This result in costs either due to non-compliance, or to efforts made to supervise members of the community despite information asymmetries.

- Increased enforcement requirements: since individuals complying with a collective order have to bear higher (static and dynamic) maladaptation costs when the order is more centrally provided, while they have less exit options (because they are fewer alternative collective orders), individuals have increasing incentives to free-ride. This result in increasing needs of enforcement, which leads to higher costs.

- The rise of private capture of the order: again, the more central the order, the less exit options for those who comply to it. Kernel's members have therefore increasing capabilities to benefit from their asymmetric position to externalize costs on peripheral members and to capture rents on them. They also have increasing incentives to do so since the field to harvest grows with the enlargement of the community (due to more centralization). Thus capture should increase.

It has to be pointed out that the three first categories of costs are "social" costs in the sense that they result in higher amount of resources spent in coordination activities, while the fourth category is essentially a matter of redistribution (which can nevertheless have consequences in terms of social costs by distorting incentives (for instance to comply to the order and resulting therefore in losses due to increased enforcement requirements; cf. iv). Figure 1 sums-up this.

\begin{tabular}{|c|c|}
\hline $\begin{array}{l}\text { Benefits } \\
\text { (Advantages of collectively settling } \\
\text { coordination problems compared to } \\
\text { more decentralized levels) }\end{array}$ & $\begin{array}{l}\text { Costs } \\
\text { (Inefficiencies of collectively settling } \\
\text { coordination problems compared to } \\
\text { more decentralized levels) }\end{array}$ \\
\hline $\begin{array}{l}\text { - Scale \& scope effects (positive } \\
\text { network effects by using common } \\
\text { standards for interactions...), } \\
\text { - Learning and specialization benefits, } \\
\text { - Reduction of collective welfare } \\
\text { losses (greater consistency of local } \\
\text { rules, internalization of externalities, } \\
\ldots \text {..) }\end{array}$ & $\begin{array}{l}\text { - Static maladaptation (increasing } \\
\text { heterogeneity of preferences), } \\
\text { - Dynamic maladaptation (reduced } \\
\text { renegotiability) } \\
\text { Cumulative Information } \\
\text { Asymmetries } \\
\text { Enforcement requirements } \\
\text { (increasing incentives to free ride), } \\
\text { - Private capture (greater incentives to } \\
\text { distort collective governance) }\end{array}$ \\
\hline
\end{tabular}

Figure 1: Factors affecting Trade-offs of Centralization

As it is understood, there is not best way to establish an order. Centralization and decentralization have their own advantages. This means that claims in favor of 
regime of pure centralization, or full decentralization, of even sole self-coordination by communities are wrong. Efficiency in matter of institutional design results from multi-level governance; i.e. the simultaneous provision of complementary orders at different degree of centralization.

Two phenomena are at play:

- "Subsidiarity": various types of coordination problems are best solved at various levels. This is due to the fact that heterogeneity of coordination preferences/needs among individuals are different for various dimension of coordination (leading to different intensities of maladaptation). This is also due to the heterogeneity in levels of benefits from centralization due to potential economies of scale, learning effects, externalities. Consequently, a mix of generic, local and interindividual governance is the best way to reduce coordination costs by addressing the various coordination problems at the right levels. These problems are well known of legal scholars when they have to manage harmonization/federalization processes.

- "Check and Balance": the various levels of provision of order can also control the weaknesses of the other levels. For instance, decentralization reduces the capabilities of capture by those belonging to the kernel of generic/central institutions and also of core members of intermediate levels institutions, since all these orders are challenged by competing orders. It also facilitates innovation. To the opposite more generic institutions can increase the enforcement capabilities of more local institutions. Indeed local institutions have inherent difficulties to generate compliance because members have exit options. A more generic institution can pursue those who did escape from a "local" jurisdiction after breaking its rules. These issues are well known of political scientists who insist on the necessity of (horizontal and vertical) decentralization of authority (Voigt, 2003, 2007).

All these calls for multilayer institutional frameworks, combining various levels of local regulation, while arbitrated by a last resort level of governance, aimed at dealing with the interdependencies that exist at the level of the society as a whole.

\subsection{The public/private tradeoff}

As pointed out in the introduction a public regulator - whatever this "regulator" is as an entity: an individual, a group or an organization - benefits from a "strong" delegation by the citizens. Let's qualify this strong delegation as a "constitutional" delegation. This delegation provides the regulator with the "legitimacy" to build/design the "collective interest" of the "citizens". It also explains why the later grant the "public" regulator with the "monopoly of legitimate violence". Indeed this monopoly allows the regulator to guarantee enforcement both within the community and against the non-members of the community. Such a constitutional delegation tends to be exclusive, since individuals are not likely to confidently renounce to a wide range of their individual liberty to benefit from regulators that would be complex to control if there were too many, and moreover would risk entering into conflict among each other. Given this exclusive character of a constitutional 
delegation and its scope, the public regulator is granted with strong "legitimacy" and "power", which makes the order it implements hard to challenge.

It is clear, however, that a constitutional delegation generates hazards for the principal-citizens. Indeed, ex-post he might be subject to without limit threat by the regulator who can use the means delegated by the citizens to extort their wealth and even enslave or kill them. A constitutional delegation being granted to secure the fundamentals rights of the citizens, if the public regulator decides to erase those rights, the citizen has only few means to protect them. He will accept to grant the defense of such fundamental rights if an only if he can get guarantee that the power of the public regulator will not be captured by individuals and groups that would be able to extort them ${ }^{5}$. This explains why systems of public authorities tend to be built around a principle of "Checks and Balances" to avoid capture. Also, the citizens tend to submit public authorities to a permanent assessment of their willingness to take into consideration their actual needs and preferences, for fear of removing their constitutional delegation to another regulator or, more credibly, to another group/individual in charge of managing the regulating organization. These explain both the pressures for (horizontal and vertical) division of power and the request for "accountability". Constitutional delegation is nevertheless of high risk for citizens, as demonstrated by the dominance worldwide of authoritarian regimes capable to escape these constraints bounding the actual power of the individuals/groups actually in charge of public regulation.

To the opposite, private regulation/governance draws from a "bounded" or "targeted" delegation by stakeholders of a right to implement a collective order. It strictly limits the range of actions by individuals over which the regulator benefits from rights to regulate. It bounds also the capability of the regulator to constrain the individuals submitted to his jurisdiction. As a consequence, private regulators have a weak capability to establish a collective regulation, but there is also little risk of capture by those agents to which authority is delegated. In particular principals can always opt-out. This leads the private regulator to permanently take into account the will and the interest of its stakeholders. Thus, the inherent bounded enforcement capability of a private regulator makes the establishment of collective order on the basis of "targeted" delegation, a solution only for the production and defense of "club goods". Indeed the stakeholders have to understand/measure their individual interest in the production of the collective good - and the individual cost of individual free riding - to accept the constraints imposed by the private regulator.

The public vs. private tradeoff in the provision of a collective order is therefore matter of capability, purpose and risk. Constitutional delegation tends to grant the public regulator with, both, strong power to actually build a collective order and with the legitimacy to define the "collective" interest (which means selecting and measuring individual preferences through a specific aggregation process), while it results in a high risk of no limit capture by the authority. Targeted and bounded delegation tends to result in only a weak capability to regulate behaviors, which

5 Of course this is depending of his initial situation in terms of effective fundamental rights. If they are not established ex ante in a state of (wild) nature, citizens tend to accept strong limitation of their freedom without much control over the possible abuses of the authority as in the serfdom contract. 
reduces the scope of the implemented collective order. This later is inevitably oriented toward efficiency and always challenged by alternative orders, which leads to be more short-termist than any public regulator which is able to impose long term interest.

As in the case of the levels of governance, the public/private tradeoff suggest combinations of mode of governance in an actual institutional framework to optimally deals with the contrasted properties of alternative governance solutions.

\section{The Global Governance Challenge}

In the context of a nation-state, there is a homothety between the centralization vs. decentralization tradeoff and the public vs. private one. Indeed, the more generic institution tend to be public — which corresponds to the State -, while the decentralized entities in charge of establishing orders have a higher probability to be private.

At the national level, the public regulator in last resort is very strong both because it is the more generic one - to the limit, individuals have no exit options and because it benefits from a strong delegation. This provides him a very strong power of capture, which strongly incites the "citizens" to influence the organization of public authorities to minimize risk of capture of its authority and abuse of it. If this risk is controlled, then the public authorities have strong means to build collective interest and to frame behavior to get it.

Local private authorities have a low capability to challenge the public order. Therefore they can be oriented toward efficiency, while being controlled by the public orders for risks to act against the general interest. There is therefore a complementarity between private and local regulations that allow agents to benefit from more efficiency - which is not the primary target of the public regulator, both because its delegation leads to balance efficiency with other criteria (like equality), and because as a generic regulator, it is not (or only weakly) challenged by alternative collective providers of order - while avoiding risk of capture - because the public regulator is able to oppose the collective interest to the private regulators (via antitrust, minimal regulatory standards and control of the private regulators' behaviors) - and because citizens try to control the public regulator. There is however a risk of collusion between public and private regulators to the detriment of the stakeholders. Again, this risk can be controlled by an appropriate organizational design of public authorities.

In the international context, this hierarchy between a public regulator overhanging all the other regulators, being able to regulate them and benefiting from a legitimate delegation from the citizens to promote the collective/public interest does no longer holds. At best, public regulators can promote the collective interest of only a sub-set of the global population. In the same time, since they are inherently local regulators in competition with other regulators, they are submitted to a competitive process by other regulators. Their capability to fairly weigh the preferences of all the citizens under their jurisdiction tends to be challenged by the fact that some categories of stakeholders have a greater ability than others to perform "forum shopping" among public regulators. The later might therefore tend to take into considerations only the interest of the more "mobile" stakeholders, which take 
them away from the balance among individual interests at the core of the definition of the collective interest. Public regulators are therefore no longer the holders of the "general" interest, which hinders their legitimacy in defining norms that would have more legitimacy than private ones, simply because they would take into account the preferences of the widest possible considered population. In addition, public regulators' enforcement capability shrinks. Within nation-states, the strength of enforcement of the public regulator draws from his ability to fully exclude in last resort outlaws from the social game. This allows the public regulator to benefit of a credible threat leading citizens to comply with the rules it designs and to accept to execute its sentences. At the international level, the public regulator no longer benefits from any power of enforcement (exclusion) in last resort; except when one considers the citizens under its jurisdiction. This generates a paradox since no public regulator exists to guarantee in last resort any global regulation that would be impossible to bypass. However, in the same time, public regulators are the only players benefiting of the needed enforcement capabilities that would be needed to implement norms to the population under their jurisdiction.

In the same way, private regulators remain local regulators in the sense that they establish an order covering only a subset of the total (global) population. However, the case may occur that at the global level, the population covered by private regulators is larger than those concerned by public regulators. In addition, their enforcement capability tends to increase because they can group at the global level all the members of a given community sharing common characteristics or common preferences (e.g. all the stakeholders involved in a given industry). This provides them with the strength to establish an order that can surpass the capability of public regulators in establishing an order in the same domain. Despite the fact that they benefit only from a weak delegation from their stakeholders, private regulators might benefit from a stronger legitimacy than public regulators to establish an order in a given domain, because they are able to take into account the preferences of all the stakeholders concerned by this domain.

The capability provided by this ability to implement a global — and therefore a "without-wide-exit-option" - order in a certain domain is a major concern because it might become "excessive" from two points of views. First, private regulators get a targeted delegation from sub-groups, while the regulation they implement can impact on non-members of these sub-groups. Since they do take into account only the interest of their principals, and since public regulators no longer control the side effects of their regulations, global private regulators can harm the interests of outsiders. In the same thought, principals of private regulators might well rely on the capability of private regulators to bypass national public regulators to implement orders that harm even the fundamental interest of those they are supposed to protect. Again, private regulators have no incentives to take into account interests of agents who are not their principals. Several examples of that might be identified in the information society, especially because private norms setters can create information spaces out of reach for national public authorities. In these spaces, private regulators can harm pre-existing rights (property rights, privacy, free speech, etc.). These concern are reinforced by the fact that the orders we are speaking of are "coordination platforms". Adopters of an order benefit and generate positive network externalities in the sense that all the "users" of a common order experience 
transaction cost reduction. There is therefore a risk of emergence of monopolistic coordination platforms that would benefit of a de facto exclusivity of coordination in certain domain. Not only these stable monopolies would induce capture of rents between kernel's members and marginal circle's members, but they also would be able to capture rents on non-members (which is for instance the case when the assets of a non-member are used by the members).

Global regulatory challenges thus draw from three facts. First, in the absence of a regulator in last resort able to take into consideration the preferences of the entire global population, some benefits of centralization cannot be obtained. In particular, discrepancies among regulations can result in substantial coordination costs (partly generated by incompatibilities, partly generated by conflicts), and public goods might no be provided at the optimal level. Second, while the power of public regulators can be captured to implement an order which does not fully reflect the interest of all the citizens - i.e. the general interest - there is no mechanism available at the global level to promote any form of general interest. Moreover, in the absence of (public) regulator in last resort able to regulate (public and private) regulators, the relationships among them are purely based on competition. It might lead some of them to abuse of dominant position, while others could be unable to ensure the sustainability of local regulations, which however would reflect the preferences of some groups of agents in certain domains. Since the competitive process does not systematically guarantee the selection of the most efficient or most desired solutions, especially when network externalities are at play (David, 1985; Katz and Shapiro, 1985; Arthur, 1989; Liebowitz and Margolis, 1994), the incapacity of a public regulator to oversee the relationships among the decentralized regulators is a concern in matter of global governance. Third, to the opposite, the strength and ability of private regulators to implement orders in certain domain at the global level reinforces the probability of capture of collective ordering by specific interests.

\section{The Regulatory Specificities of the Cyberworld}

The challenges raised by problems of global concern in the absence of a framework well adapted to global regulation - especially in the absence of a global regulator in last resort and of actual capabilities by public regulators to control private ones - are reinforced in the specific cases of the regulation of the information society. Indeed, digital technologies make it possible at a very low cost to implement orders on a very decentralized basis. First, digital technologies empower individual agents with the ability to implement self-enforcing property rights and contracts over information goods. Indeed, the code - to rely on Lessig's categories - allows any agent that produce information or knowledge to encrypt it so as to control access and use. It is a way to decentrally establish property rights, without relying on a third part regulator responsible for enforcement (in exchange of a control of the legitimacy of claims). Second, the principle of end-to-end connectivity allows agents to design information spaces in which they control how agents interact. The ability to build and control access to information spaces whatever they are from mailing lists to sophisticated extranets - provides with a power of inclusion/exclusion in/from a platform of coordination is the key resource for the regulation of (virtual) communities since this provides with a power of 
exclusion in case of non-compliance with the rules in use in the community. Both technical capabilities strongly reduce the cost of implementing an order, especially because they drive enforcement costs down. In particular, they tend to reduce the economies of scale and the benefits of specialization (in matter of supervision) linked to centralization (table 1), thus reducing the range of situation in which the tradeoff centralization vs. decentralization is in favor of the former. Indeed, exclusion in last resort does not require the use of physical strength, but only an ability to fake information. In addition tracking technologies allow at a very low cost to supervise behaviors. Not only exclusion and supervision costs are driven down, but the low cost of the technology makes the entry ticket (i.e. the minimum level of fixed cost) available for a great deal of economics agents.

Lastly, these technologies allow faking contents and exchanges of information, which reinforce in particular the capability of regulators to bypass control in last resort of their behavior by those in charge of the collective interest. All this happens in a context in which the technological revolution and the globalization of networks challenge most of the traditional regulatory frameworks that were settled in a different technological context and at a time in which the cost of circulation of information was much higher. Traditional regulatory frameworks, usually organized at the national level, are no longer performing according to the needs.

Thus, the problems raised by the changing regulatory capabilities provided to agents by digital technologies do not change the nature of the global regulatory challenge. It only enlarges their scope due to the empowerment of individuals against the traditional public regulators. Is it however a threat? Indeed, the fact that governmental constraint is no longer the sole enforcement tool and that individuals car form global communities regulating certain domains according to their preferences, can be considered as a positive factor for challenging the ability of those in control of governments to capture the strength of public regulators to their own benefits.

However, the cyber-world deals with resources that have a "public" nature. More precisely, the governance of digital networks and of contents circulated, stocked and produced on these networks deal with two types of resources information and knowledge, on the one hand, open coordination platforms (which encompass both technical standards for interoperability of digital technologies to social spaces allowing agents to coordinate, exchange and share resources), on the other hand - which are not "rival", while they tend to become more "excludable" with digital technologies". This raises a major challenge since the access to these "public" resources can be artificially and inefficiently restricted. The incentives to do so are obvious: the exercise of monopoly power and the capture of rents. Traditional property rights system try to balance the necessity to provide incentives to produce and to maintain resources with the collective interest, in particular by bounding owners' ability to forbid access to their resources when inefficient, generally because it prevents the use of complementary resources (which is often the considered case in

6 "Public" (or collective) goods are characterized by non-rivalry in consumption - the use of the good by one agent does not diminish its availability for another agent - and nonexcludability - it is costly and sometimes impossible to exclude a user from the access or the use of the good. 
anti-trust policies) or because one deal with a non-rival resource (which explains the many restrictions to property sovereignty in matter of intangible assets). Public regulators therefore bound the exclusivity of rights of access and rights of use. This is not longer possible in the cyber-world, due to the capability of the later to selfimplement their property rights without relying on the former. In the same time, the ability to fake use and exchanges of information within specific communities allow these communities to implement orders that could harm third parts. For instance, members of some communities can access to contents distributed under certain conditions by their owners, and decide to use these contents within the community without complying any longer with the conditions imposed by the initial "owners". Also, communities could well rely on hidden platforms of coordination to manage collusive behaviors.

These threats are particularly strong in the information society because of the long-term sustainability of monopolies. Indeed, the economics of the digital economy is characterized by fixed costs and network externalities (Shapiro and Varian, 1999; Brousseau and Curien, 2007), which facilitate the emergence and implementation of monopolies. This trend is reinforced by the fact that standards of interface are essential in this universe of modular technologies. Due to network effects, the establishment of these standards can be based on a decentralized process of adoption by users. Dominant players have thus strong incentives to manipulate the diffusions processes of these standards in order to favor solutions that enhance their market power. The control of standards of interfaces is essential because it leads to influence entries and the dynamic of competition and technical evolutions. It might therefore lead to endless domination capabilities, or at least to downgrade the contestability of most dominant position.

Thus, digital network and technologies considerably reinforce the capabilities of individuals and communities to develop regulations and orders fitting to their specific needs in a context where the dynamic of the competitive process can be hindered in the long run by dominant players. At the national level it can result in a equilibrated balance of power between public and private regulators, since the former still hold the capability to physically constrain the later, which in turn can escape the jurisdiction of the former. It is however a major concem at the international level since nobody is really able to counter-balance the power of private regulators, which can rely on network and viral effects to establish and exercise strong market power, and which can also by-pass most of the efforts made by (de facto local) public regulators to promote collective interest or to hinder their market power.

\section{Several Possible Governance Frameworks}

To control the risk of an endless capture of the governance/regulatory power by private entities driven by the sole interest of their stakeholders (that might also collude with some dominant public regulators aimed at promoting the only interest of their citizens), an authority responsible in last resort for guaranteeing at least an open and fair competition among the various (public and private) entities establishing orders is essential. Preserving competition is not only a good way to avoid the establishment of orders that would lead to monopoly capture for long 
periods, it is also a mean to incite the various "sponsors" of orders to negotiate to manage compatibilities among orders. This is essential since in case no order/platform or coordination is able to definitively surpass its competitors by becoming the only available solution at the global scale, the various stakeholders might exercice pressures on the "sponsors" of the alternative orders to harmonize at least interfaces to decrease transaction costs. If members of the kernels get rid of their expectations to impose their first best order at the global level, their second best option is to negotiate with sponsors of competing orders to avoid defection by their stakeholders who are simply seeking for costless platforms of coordination. Such negotiations should result in global orders that would care of more individual interests - that would be more inclusive - than the order resulting from pure competition among alternative orders, since the interests taken into account by several "sponsors" of various orders will be considered.

Thus, ideally, the information society needs a last resort entity able to control the establishment of non-contestable monopolies providing collective orders. It would be responsible for controlling the actual performance of the various orders established by various entities; which at least require a minimal transparency and therefore limits to the rights/capabilities to fake uses and exchange of information. Indeed the last resort regulator should be able to control what is happening in closed coordination spaces. Rules of disclosure rule and bounded encryption capabilities should therefore be implemented.

Second, the regulator in last resort should be able to guarantee that those promoting orders corresponding to the preferences of their stakeholders, would not be prevented to implement it, as providers of alternative orders or opportunistic individuals driven by hit and run predation strategies would be able to bypass their bounded enforcement capabilities. This role of last resort enforcer is well justified in Milgrom et al. (1990) and Greif et al. (1994) and corresponds to one of the benefits of centralization highlighted above.

Third, and also in line with our analysis of multilevel governance, a last resort authority able to implement an order at the most central level is needed to internalize externalities and maximize collective interest. To optimize these effects, this authority should be of a public nature, since a strong delegation will bring it to take into account a wider set of domains and interest than a narrow one. Since interdependencies can be expected among domains, the regulator in last resort would ideally not only benefit from delegation by the widest possible population, it should also benefit from the widest possible delegation (in terms of domains) by the stakeholders.

Therefore, there are several reasons calling for the emergence of a regulator of last resort in the information society; and even calling for the last resort regulator of a public nature. It is well known, however, that today there is no process under way of emergence of a global government. However it should be recognized that there are several possible path of emergence of such regulators in last resort, and that these path can lead to very different models.

The ICANN (Internet Corporation for Assigned Names and Numbers; http://www.icann.com/) is a good candidate for being a last resort regulator of the Internet and more generally of the information society because, as argued elsewhere (Brousseau, 2004, 2007), it owns and maintains the essential resources guaranteeing 
access to the Internet: i.e. the addressing system. Indeed ICANN decisions can result in de facto excluding from the Internet the services providers or the users that would not comply with ICANN's will. ICANN consistently claims that it never used this capability because it seeks to be only a "technical" regulator of the Internet, responsible for its technical performance only. It is nevertheless obvious that the capability to control access to the Internet linked to the control of the addressing system is a key resource available and needed by any regulator in last resort, since it allows to forbid actual implementation of orders inconsistent with the principles promoted by the last resort regulator. Since ICANN is not independent from the US Government, because its prerogatives draws from a delegation contract by the Federal Government, because implementation of its decisions rely on Verisign that is also an agent of the US Government, and also because ICANN is incorporated in the US, it is clear that this organization is not exactly what we usually qualify as a self and private regulator. It is a private entity to which governmental power is delegated.

The ICANN model is therefore a model corresponding to one possible form of public governance at the global level: hegemony. A hegemonic model relies on the recognition of a strong delegation by citizens (who initially delegated the provision of their fundamental rights to their "national" government) to another government that become the hegemon. This could happen because this hegemon is able to provide a "service" of higher quality than the one delivered by the "national" government, and because the later is unable to avoid this bypass of delegation by its citizens. All these individuals and groups of interest adhering and involved in the processes of claimed "self-regulation" promoted by ICANN consider that this organization, backed by the US Government and by the US constitution, provides a framework aimed a regulating the information society and the information economy according to principles that better fits their interest than the alternative framework promoted by their national governments, either for political reasons - as it is the case for many citizens of non-democratic states - or for economic reasons - as it is the case for economic agents originating from many countries with high intensity of state's direct intervention in the economy. The advantage of a hegemonic model is that it provides an already existing framework in which a last resort regulator is able to centrally provide components of a generic order. Its limit lies in the fact that the hegemon does not consider all the principals providing him with a "public" delegation as belonging to the same circle. There are obviously full rights citizens (who benefit for instance of "voice" - cf. Hirshman (1970) - and right to vote) and second rank citizens (who only benefit a right to leave). The authority in charge of establishing a common order will higher rank the preferences of the first category than those of the second one.

One of the alternative models is obviously the one promoted by the WSIS process (World Summit on the Information Society; http://www.itu.int/wsis). Here the underlying model is clearly the one of a confederation in which the holders of strong delegation by the citizens - the Governments - accept to delegate some of their rights to establish an order to a common entity. The weakness of a confederal model lies in the fact that the national governments do not definitively give up with their prerogatives to regulate. They often remain the holders of enforcement capabilities and responsible in last resort for the compliance of their citizens with the rules decided by the confederal entity. This provides them with a de facto veto power 
over any potential confederal regulation, which bounds capability to promote the general interest (while it protect interest of those who have the national governments' ear). Indeed, there is no direct delegation between the citizens and the entity in charge of the global/last resort governance/regulation, which bounds both the capability and the legitimacy of the confederal entity in imposing binding regulations to the national regulators. This explains well why the WSIS process is so slow to take off and seems so unlikely to result in actual regulations. On the one hand, there are little chances to reach agreements among governments and nations that have such contrasted preferences in matter of regulating information exchanges, access to knowledge and platforms of coordination. On the other hand, several major players and in particular the US Government and private regulators, have interest in promoting alternative models of global regulation. The process initiated by the WSIS has therefore little chances to result in the emergence of a public regulator in last resort really able to cope with the preferences of most of the global citizens (while of course it is an important laboratory of ideas and process to allow expressions of a wide range of opinions).

The last model is the one of a federation, in which a federal entity gets strong delegation from the citizens - either directly or via a process of full and definitive transfer of prerogatives from national government to the federal one. Today, such a process does not exist at all at the global level. However, it is to a certain extent what is happening in many domains, generally, in regional unions, and in Europe in particular. As well illustrated by the performance of the US federal system, when a federal government benefits from a "constitutional" delegation by citizens, it benefits from an actual authority to implement an order aimed at guaranteeing the collective interest of its constituency, while being submitted in the same time to challenges by decentralized holders of public or private delegations to provide all kind of orders. A federal system is therefore much preferable, everything equal, to any alternative since it actually allows distribution of governance prerogatives according to the principles of multi-level and multi-mode governance highlighted in the first section of this chapter. It is clear, however, that such a model requires a slow process of institutional evolutions, through which - even by being submitted to short terms back and forth movements - integration and enlargement result from progressive discovery, negotiation and adhesion of/to common principles of collective regulations. The problem with this option in the current global and technological dynamics is that alternative regimes of global regulations could well emerge either on the basis of the hegemonic model or on the basis of fragmented private regulations.

Economics can well meet ethics in recognizing the normative necessity to benefit from a global and legitimate regulator in last resort. It might in the same time lead to recognize that the combined forces of private interests and biased competitive selection processes could lead to orders that would not fit to this first best. Economics propose however tools to assess the respective advantages and costs of these alternative solutions, that could be of some usefulness to choose among the possible available models of regulatory architecture for the information society. 


\section{References}

Arthur, Brian W. 1989, "Competing technologies, increasing returns, and lock-in by historical events", Economic Journal, 99, 116-131.

Barzel, Yoram .1989. Economic Analysis of Property Rights, Cambridge: Cambridge University Press.

Bonacich, Phillip, 1987, "Power and Centrality: a Family of Measures", American Journal of Sociology, 92: 1170-1182.

Brousseau, Eric. 2004a. "Property Rights in the Digital Space", in Enrico Colombatto (ed) Companion to_Economics of Property Rights, Cheltenham, UK and Northampton, MA, USA: Edward Elgar Pub, 2004, 438-472.

Brousseau, Eric. 2004b. "Property Rights on the Internet: Is a Specific Institutional Frame needed", Economics of Innovation and New Technology, 13(5) July 2004, 489-507.

Brousseau, Eric. 2007. "Multilevel Governance of the Digital Space: Does a "second rank" Institutional Framework exist?" in Eric Brousseau and Nicolas Curien (eds) Internet Economic, Digital Economics, Cambridge,UK: Cambridge University Press.

Brousseau Eric and Nicolas Curien (eds), 2007, Internet Economic, Digital Economics: Principles, Methods and Applications, Cambridge,UK: Cambridge University Press.

Brousseau, Eric and Emmanuel Raynaud. 2006. "The Economics of Private Institutions: an Introduction to the Dynamics of Institutional Frameworks and to the Analysis of Multilevel, Multitype Governance", Mimeo, EconomiX, University of Paris X.

Brousseau, Eric and Emmanuel Raynaud. 2007. "The Economics of Multilevel Governance", Mimeo, EconomiX, University of Paris X.

David, Paul A. 1985, "Clio and the economics of QWERTY", American Economic Review, 75, 332-337.

Greif, Avner 2006, Institutions and the Path to the Modern Economy: Lessons from Medieval Trade, Cambridge University Press.

Greif, Avner, Paul M. Milgrom, Barry Weingast. 1994, "Coordination, Commitment and Enforcement: the Case of the Merchant Guild", Journal of Political Economy, 102(4), 745-776. 
Hanneman, Robert A. and Mark Riddle. 2005, Introduction to social network methods, Riverside, CA: University of California, Riverside (published in digital form at http://faculty.ucr.edu/ hanneman/ ).

Hirshman Alfred O. 1970, Exit, voice and loyalty, Response to decline in firms, organizations, and States, Cambridge, Mas., Harvard University Press.

Katz, Michael L., Carl Shapiro. 1985, "Network externalities, competition, and compatibility”, American Economic Review, 75(3), 424-440.

Lessig, Lawrence.1999. Code and other Laws of Cyberspace, New York: Basic Books.

Liebowitz, Stephen J., Margolis, Stephen E. 1994, "Network Externality: An Uncommon Tragedy", Journal of Economic Perspectives, Spring, 133-150.

Milgrom, Paul, Douglass C. North and Barry Weingast. 1990. "The role of institutions in the revival of trade: the law merchant, private judges, and the Champagne fairs", Economics and Politics, 2(1). March, 1-23.

North, Douglass C. 1990. Institutions, Institutional Change and Economic Performance, Cambridge: Cambridge University Press.

Oates, Wallace E. 1972. Fiscal_Federalism. New York: Harcourt Brace Jovanovich.

Oates, Wallace E. 1999. "An Essay on Fiscal Federalism.” Journal_of_Economic Literature 37: 1120-1149.

Ostrom, Elinor, and James Walker. 1997. "Neither Markets nor States: Linking Transformation Processes in Collective Action Arenas." In Perspectives_on_Public Choice:_A_Handbook, edited by Dennis C. Mueller. Cambridge: Cambridge University Press, 35-72.

Rosenau, James N. 2001. "Strong Demand, Huge Supply: Governance in an Emerging Epoch." Paper prepared for the Conference on Multi-Level Governance: Interdisciplinary Perspectives, sponsored by the Political Economy Center of the University of Sheffield. Forthcoming in I. Bache M. Flinders (eds) Multi-Level Governance, Oxford, Oxford Univeristy Press, 2004.

Shapiro Carl and Hal R. Varian. 1999. Information and Rules, Cambridge: Harvard Business School Press.

Voigt, Stephan (ed). 2003. Constitutional Political Economy, Chltenham: Edward Elgar Pub ."The International Library of Critical Writings in Economics series ", vol 166.

Voigt, Stephan. 2007. "Constitutional Political Economy - Analyzing the most basic layer of formal institutions", in Eric Brousseau, Jean-Michel Glachant, New 
Institutional Economics, a Guidebook, Cambridge \& New York: Cambridge University 